\title{
Does Discharge Destination Matter after Total Knee Arthroplasty? A Single-Institution Korean Experience
}

\author{
Vivek Tiwari, MS (Ortho), DNB (Ortho) ${ }^{1, \star}$, Chang Kyu Park, MD, Seon Woo Lee, $\mathrm{MD}^{2}$, Moon Ju Kim, MS², \\ Jeong Seong Seong, $\mathrm{MS}^{2}$, and Tae Kyun Kim, $\mathrm{MD}^{2,3}$ \\ ${ }^{1}$ Department of Orthopaedics, All India Institute of Medical Sciences, Bhopal, MP, India; ${ }^{2}$ Department of Orthopaedic Surgery, Joint Reconstruction Center, Seoul \\ National University Bundang Hospital, Seongnam; ${ }^{3}$ Department of Orthopaedic Surgery, Seoul National University College of Medicine, Seoul, Korea
}

\begin{abstract}
Purpose: To compare extended care facility (ECF) and home as discharge destination after total knee arthroplasty (TKA) at a single high-volume tertiary center in South Korea.

Materials and Methods: We retrospectively analyzed 1,120 primary TKAs (614 patients) performed between January 2012 and December 2013. A telephonic survey was conducted to determine discharge destination. The data reviewed included demographic and surgical data, functional outcome at 2 years and complications within 3 months.

Results: ECF and home received 316 patients (51\%) and 298 patients (49\%), respectively. The ECF group had more bilateral TKA patients than the home group ( 272 vs. $234 ; \mathrm{p}=0.014$ ) and more patients with additional hospital stay ( 44 vs. 22; $\mathrm{p}=0.009$ ). A higher tendency of complications was seen at home $(n=8,2.7 \%)$ than the ECF $(n=2,0.6 \%)(p=0.057)$. No significant differences were found in any functional outcome measure. Home patients had better patient satisfaction than ECF patients (81.9\% vs. $54.3 \%$; $\mathrm{p}<0.001)$.

Conclusions: Patients who returned home after discharge had similar functional outcome at 2 years after surgery and higher patient satisfaction than those in the ECF in spite of the higher tendency of complications. Patients need adequate counseling and education regarding advantages and limitations of the two discharge destinations.
\end{abstract}

Keywords: Knee, Arthroplasty, Discharge, Home, Extended care facility

\section{Introduction}

The destination where patients receive postsurgical rehabilitative care after discharge, following total knee arthroplasty (TKA), has important clinical implications. After TKA, patients are discharged to either of the two discharge destinations, home or

Received August 2, 2017; Revised (1st) August 27, 2017;

(2nd) September 7, 2017; Accepted September 7, 2017

Correspondence to: Tae Kyun Kim, MD

Department of Orthopaedic Surgery, Joint Reconstruction Center, Seoul National University Bundang Hospital, 82 Gumi-ro 173beon-gil, Bundang-gu, Seongnam 13620, Korea

Tel: +82-31-787-7196, Fax: +82-31-787-4056

E-mail: osktk@snubh.org

*The first two authors contributed equally to this study.

This is an Open Access article distributed under the terms of the Creative Commons Attribution Non-Commercial License (http://creativecommons.org/licenses/by-nc/4.0/) which permits unrestricted non-commercial use, distribution, and reproduction in any medium, provided the original work is properly cited. extended care facility (ECF), with the latter including inpatient rehabilitation facility (IRF) and skilled nursing facility $(\mathrm{SNF})^{1)}$. However, in South Korea, the clinical pathway for discharge to a SNF is inadequately developed. The implementation of the bundled payment system has brought newer developments in patient care and the clinical pathways after $\mathrm{TKA}^{1,2)}$. Its introduction has resulted in an increased need for efficient delivery of postoperative care and subsequently has led to an increasing interest in the selection of discharge disposition after TKA. Although this system has not yet found its place in the Korean healthcare system, it is expected to be introduced soon in the South Korean medical system.

In the West, multiple studies have investigated the effect of discharge destination on postoperative functional outcomes and complications after TKA ${ }^{1,3,4)}$. However, a paucity of available data exists on this subject in Asian countries, and no such data are available in South Korea. Moreover, we could not find any study evaluating and comparing functional outcomes at 2 years 
after TKA. Furthermore, the influence of bilateral surgery on the choice of a discharge destination has not been investigated. Therefore, we aimed 1) to identify the status of discharge destination after TKA at this single high-volume tertiary center in South Korea; 2) to determine whether demographic and surgical factors, including bilateral TKAs, differ between patients discharged to an ECF and those discharged to home; and 3) to assess whether patients managed at ECFs had less complications, better functional outcome at 2 years, and better patient satisfaction than those cared at home.

\section{Materials and Methods}

\section{Study Design and Setting}

We retrospectively reviewed all primary TKA procedures performed at a single high-volume tertiary care institution in South Korea between January 2012 and December 2013. During the above-mentioned period, 1,371 primary TKAs were performed in 764 patients. The patients were treated with either unilateral or bilateral TKA, performed either in a staged or simultaneous manner based on the age and comorbidity profiles of the patients. The second procedure in staged bilateral TKA was performed 1 week after the index surgery.

\section{Surgical Procedure and Rehabilitation}

All the surgeries were performed by a single surgeon (TKK) using the medial parapatellar approach. All the TKA procedures were performed using either a fixed bearing system (Genesis II Total Knee System; Smith \& Nephew, Memphis, TN, USA) or a mobile bearing system (e.motion Total Knee System; B. BraunAesculap, Tuttlingen, Germany). A posterior-stabilized design was used in all knees. The selection of the implant was made at the surgeon's discretion, without any preset selection criteria. The patella was routinely resurfaced, and all the implants were fixed with cement. Postoperative care was delivered according to a standardized clinical pathway.

\section{Description of Discharge and Follow-up Routine}

All the patients were discharged as per our standardized institutional protocol. The unilateral, simultaneous bilateral, and staged bilateral cases were discharged on the 7th, 10th, and 14th postoperative day, respectively. Those with wound problems, medical problems, inadequate pain control, or severe patient anxiety were allowed additional hospital stay. As part of the discharge planning, the patients were provided with information describing the postoperative care, including complications and rehabilitation. The decision for the discharge destination was made at the patient's discretion without any specific intervention. The patients were regularly followed up based on the standardized care pathway, at 2 weeks, 6 weeks, 3 months, 6 months, 1 year, and annually thereafter. At each follow-up visit, data including complications and postoperative function were prospectively collected. Postoperative function was assessed based on motion arc, American Knee Society (AKS) score ${ }^{5}$, Western Ontario and McMaster Universities Arthritis index (WOMAC) score ${ }^{6}$, and 36-item Short-Form Health Survey (SF-36) score ${ }^{7}$.

\section{Telephone Survey}

We conducted a telephone survey on all the patients to collect data regarding their discharge destination. As no previous study had been conducted with a similar purpose, we invented the survey questionnaire form after several research consensus meetings (Appendix 1). An independent investigator (JSS) called each patient twice a week for 2 consecutive weeks until the patient could be contacted to reduce missing responses. In the survey, we enquired about the type of discharge destination (ECF or home). In the ECF group, we asked about the admission route for ECF, reasons for selection, location of the facility, length of stay at the ECF, rehabilitation modality provided, and satisfaction with the discharge destination. In the home group, we asked who provided the postoperative care and about satisfaction with the homebased care. We also asked about the reasons for dissatisfaction of the unsatisfied patients in both groups.

\section{Medical Record Review}

We reviewed the prospectively collected clinical data from the medical records of all the patients. The data included demographic characteristics such as age, sex, weight, height, and body mass index (BMI) and surgical factors such as the number of bilateral TKA patients and those who required additional hospital stay. We excluded patients who had diagnoses other than primary osteoarthritis, had systemic comorbidities affecting knee function, were lost to 2-year follow-up, and had missing responses to a telephone survey. As a result, 1,120 TKAs in 614 patients ( $80 \%$ of the initial sample) were analyzed (Fig. 1). The primary outcome variables were WOMAC scores for pain, stiffness, and function at 2 years. The secondary outcome variables were motion arc, AKS score, and SF-36 score at 2 years; complications within 3 months after surgery, including wound complication, deep infection, deep vein thrombosis, and urinary tract infection; and patient satisfaction. 


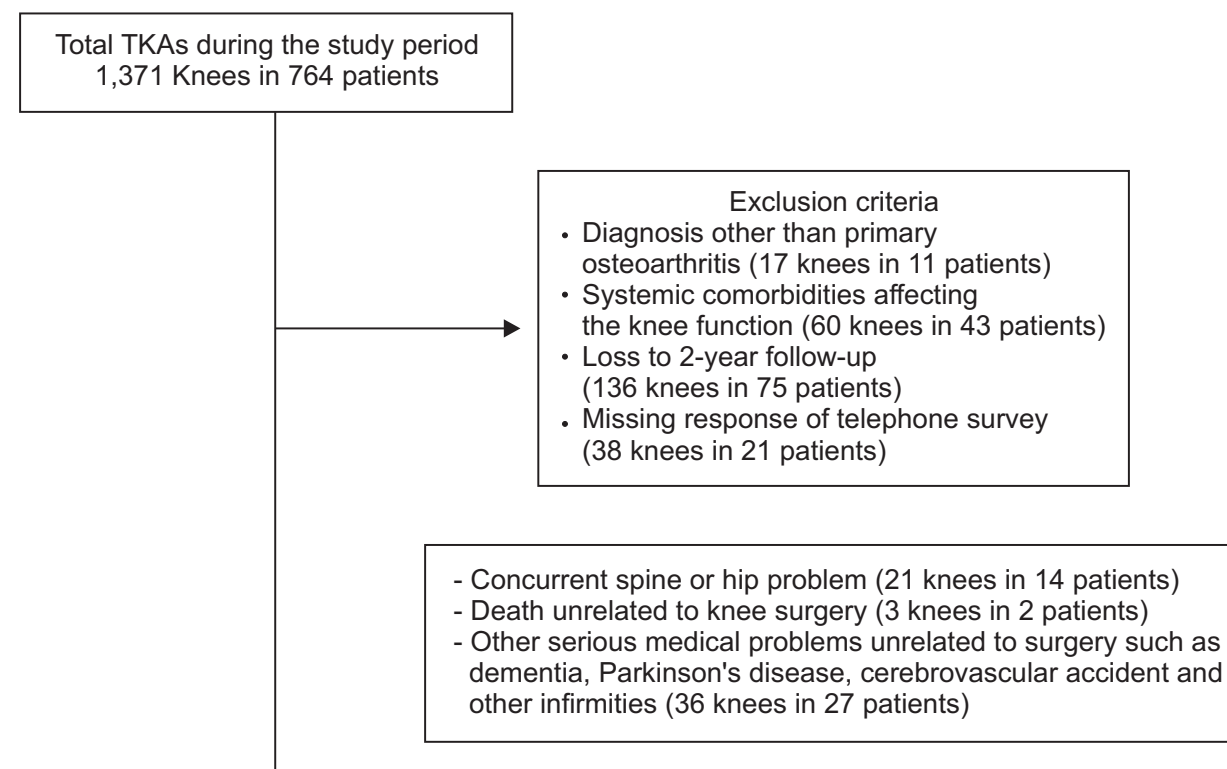

Final analysis

1,120 Knees in 614 patients $(80 \%)$

\section{Statistical Analysis}

All statistical analyses were performed using SPSS ver. 18.0 (SPSS Inc., Chicago, IL, USA), and p-values of $<0.05$ were considered significant. Quantitative variables were expressed as mean and standard deviation. Continuous and categorical variables were compared using the Student $t$ and chi-square tests, respectively. To determine whether our sample size was adequate, we performed a priori power analysis using the two-sided hypothesis test at an alpha level of 0.05 and a statistical power of $80 \%$ to detect a minimal clinically important difference in WOMAC scores at 2 years after TKA. Sixty-four knees were required for each group to detect a $5^{\circ}$ difference in motion arc and $6 \%$ difference in functional scores, which we considered as the minimal clinically important difference (motion arc was measured to the nearest $5^{\circ}$, and a $6 \%$ difference in maximum score has been suggested as the minimal clinically important difference for WOMAC and SF-36 scores $\left.{ }^{8}\right)$. Thus, the sample size used in this study was regarded as adequate.

\section{Results}

More than half of the patients were discharged to ECFs after undergoing TKA. During the study period, 316 patients (51\%) were discharged to ECFs, while 298 patients (49\%) were discharged to home. The most common reason for selecting an ECF rather than home care was to aid in postoperative rehabilitation (69\%). More than half (52\%) of the patients stayed from 2 weeks to 1 month duration in the facility. Most (78\%) of them received gradually increasing passive range of motion (ROM) exercises by physicians or family members, performed ROM exercises themselves, and used continuous passive motion. Among the patients discharged to home, $45 \%$ had to take care of themselves as opposed to receiving care from family members (39\%), home visiting nurse service $(2 \%)$, or any nearby outpatient care agency (14\%) (Table 1).

A greater proportion of the patients who underwent bilateral TKAs and those who had prolonged stay in the primary care institution went to an ECF rather than home (Table 2). Eightysix percent of the patients in the ECF group $(n=272)$ underwent bilateral TKA as compared with $79 \%$ in the home group $(n=234)$ $(\mathrm{p}=0.014)$. Among the patients who required extended hospital stay, $67 \%(n=44)$ went to an ECF and only $33 \%$ selected home as their discharge destination $(\mathrm{n}=22)(\mathrm{p}=0.009)$. The patients in the ECF group tended to have higher BMIs than those in the home group ( $\mathrm{p}=0.051$ ), although the mean height and weight of the two groups were similar. No significant difference in mean age (ECF vs. home; 73.1 years vs. 73.2 years) or sex distribution (ECF vs. home; $95 \%$ females $[n=301]$ vs. $93 \%$ females $[n=276]$ ) were found between the two discharge groups.

The ECF group tended to have lower complication rates, had similar functional outcome at 2 years, and had a less proportion of satisfied patients than the home group. Eight patients experienced a complication within 3 months after TKA in the home group as compared with only two patients in the ECF group 


\section{Tiwari et al. Discharge Destination after Total Knee Arthroplasty}

Table 1. Results of the Telephone Survey Regarding Discharge Destination

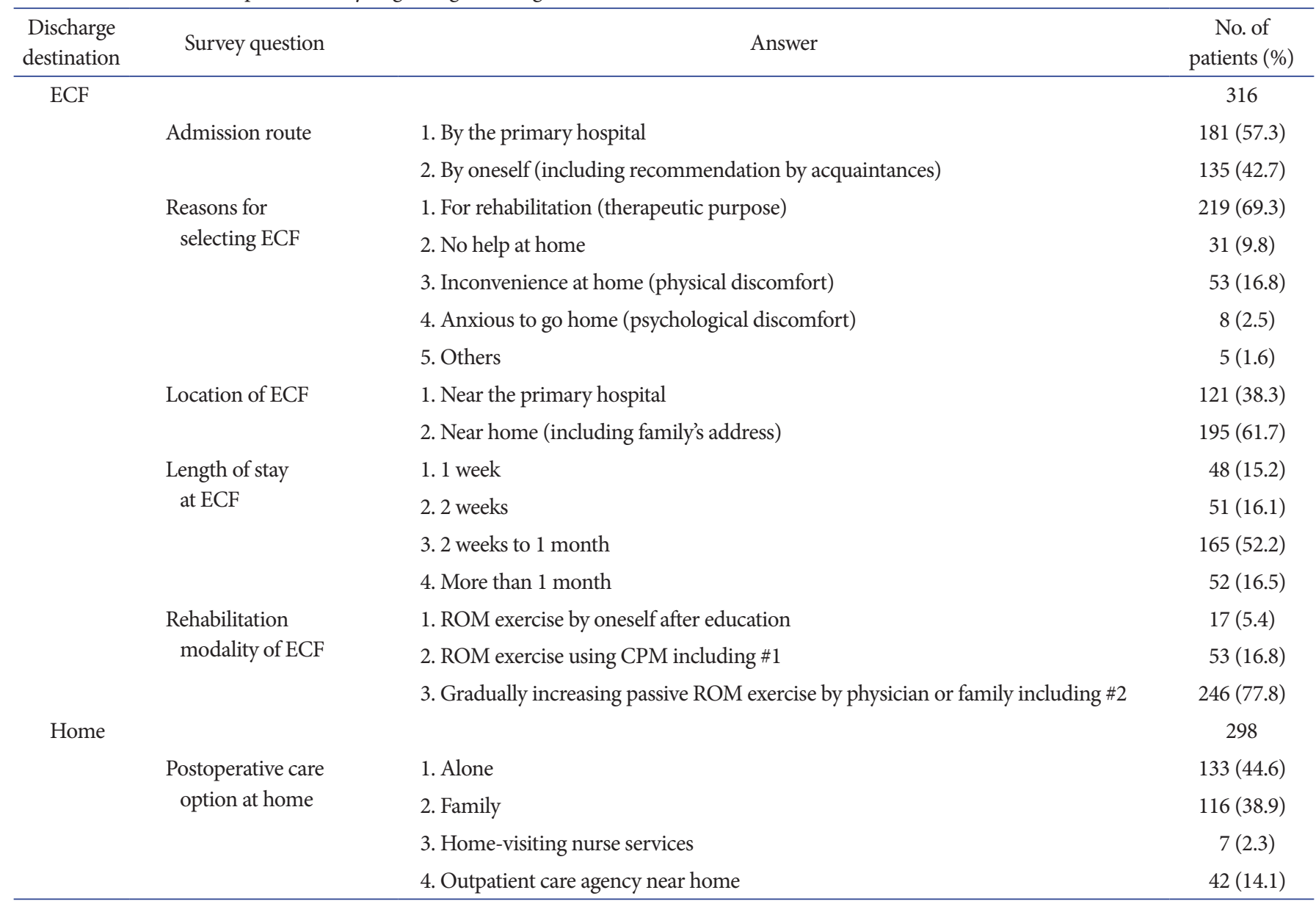

ECF: extended care facility, ROM: range of motion, CPM: continuous passive motion.

Table 2. Comparison of Demographic and Surgical Factors

\begin{tabular}{lccc}
\hline \multicolumn{1}{c}{ Variable } & $\begin{array}{c}\text { ECF group } \\
(\mathrm{n}=316)\end{array}$ & $\begin{array}{c}\text { Home group } \\
(\mathrm{n}=298)\end{array}$ & p-value \\
\hline Demographic & $73.1 \pm 6.1$ & $73.2 \pm 6.1$ & 0.804 \\
Age $(\mathrm{yr})$ & $301(95.3)$ & $276(92.6)$ & 0.170 \\
Gender (female) & $154.8 \pm 7.2$ & $153.2 \pm 6.6$ & 0.164 \\
Height $(\mathrm{cm})$ & $62.4 \pm 9.2$ & $62.9 \pm 9.5$ & 0.338 \\
Weight $(\mathrm{kg})$ & $27.3 \pm 3.6$ & $26.7 \pm 3.1$ & 0.051 \\
BMI $\left(\mathrm{kg} / \mathrm{m}^{2}\right)$ & & & \\
Surgical factor & $272(86.1)$ & $234(78.5)$ & 0.014 \\
Bilateral surgery & $44(13.9)$ & $22(7.4)$ & 0.009 \\
Additional hospital stay & & & \\
\hline
\end{tabular}

Values are presented as mean \pm standard deviation or number (\%).

ECF: extended care facility, BMI: body mass index.

$(\mathrm{p}=0.057)$ (Table 3). Wound complication was the main problem in both groups. The mean AKS scores for pain, knee, and function; WOMAC scores for pain, stiffness, and function; SF-36
Table 3. Comparison of Complications

\begin{tabular}{lccc}
\hline \multicolumn{1}{c}{ Variable } & $\begin{array}{c}\text { ECF group } \\
(\mathrm{n}=316)\end{array}$ & $\begin{array}{c}\text { Home group } \\
(\mathrm{n}=298)\end{array}$ & p-value \\
\hline Wound complication & 2 & 4 & - \\
Deep infection & 0 & 1 & - \\
Deep vein thrombosis & 0 & 1 & - \\
Urinary tract infection & 0 & 2 & - \\
Total (\%) & $2(0.6)$ & $8(2.7)$ & 0.057 \\
\hline
\end{tabular}

ECF: extended care facility.

scores for physical and mental component summary scales; and motion arc were found to be similar in the two groups at 2 years' follow-up (Table 4). A significantly greater proportion (81.9\%) of patients $(\mathrm{p}<0.001)$ in the home group than that in the ECF group (54.3\%) was satisfied with their discharge destination (Table 5). Of the 50 patients who were unsatisfied with ECF, 30 (60\%) complained of unavailability of sufficient postoperative care except rehabilitation (Table 6). Among the unsatisfied patients in the 
Table 4. Comparison of Functional Outcome

\begin{tabular}{lccc}
\hline \multicolumn{1}{c}{ Variable } & $\begin{array}{c}\text { ECF group } \\
(588 \text { knees } \\
\text { /316 patients) }\end{array}$ & $\begin{array}{c}\text { Home group } \\
(532 \text { knees } \\
\text { /298 patients })\end{array}$ & p-value \\
\hline Motion arc & & & \\
Flexion contracture & $0.5 \pm 1.8$ & $0.6 \pm 1.8$ & 0.068 \\
Maximum flexion & $131.9 \pm 11.8$ & $133.2 \pm 12.1$ & 0.693 \\
AKS score & & & \\
Pain (50) & $47.9 \pm 4.1$ & $48.1 \pm 4.2$ & 0.531 \\
Knee (100) & $95.3 \pm 6.0$ & $96.1 \pm 6.0$ & 0.118 \\
Function (100) & $93.2 \pm 9.6$ & $93.3 \pm 9.7$ & 0.960 \\
WOMAC score & & & \\
Pain (20) & $2.9 \pm 3.1$ & $2.8 \pm 3.3$ & 0.842 \\
Stiffness (8) & $2.0 \pm 1.8$ & $1.9 \pm 1.7$ & 0.385 \\
Function (68) & $16.4 \pm 1.2$ & $16.0 \pm 12.0$ & 0.341 \\
SF-36 score & & & \\
Physical CS & $43.3 \pm 8.9$ & $44.9 \pm 8.4$ & 0.091 \\
Mental CS & $54.2 \pm 10.7$ & $53.0 \pm 11.1$ & 0.252 \\
\hline
\end{tabular}

Values are presented as mean \pm standard deviation.

ECF: extended care facility, AKS: American Knee Society, WOMAC: Western Ontario and McMaster Universities Arthritis index, SF-36: 36Item Short Form Health Survey, CS: component summary.

home group $(\mathrm{n}=23)$, the most common cause was psychological anxiety (48\%).

\section{Discussion}

The choice of discharge destination following TKA and its economic, clinical, and social implications are controversial. Many studies on this aspect, mostly from the West, have been conducted over the last decade ${ }^{2,9-25}$. However, in an extensive literature search, we could not find any previous study about the status of discharge destination and its effect on functional outcome and patient satisfaction after TKA in an Asian country. To the best of our knowledge, this is the first study to address such issues in an Asian population.

We found that more than half of the patients were discharged to an ECF after TKA. This finding contradicts those of other published studies, mostly from the West, that reported that home-based care was more popular than an inpatient setting $^{1-4,9-14,16-22,24,25)}$ (Table 7). Such results demonstrate the current pattern of discharge disposition in South Korea, which does not seem to follow the Western pattern, probably as the bundled payment system has not been introduced yet in the country. As about $55 \%$ of the cost incurred in TKA is for post-acute care and
Table 5. Comparison of Satisfaction Level

\begin{tabular}{lccc}
\hline Variable & ECF group $(\mathrm{n}=316)$ & Home group $(\mathrm{n}=298)$ & $\mathrm{p}$-value \\
\hline Unsatisfied & $50(16.0)$ & $23(7.7)$ & \\
Neutral & $93(29.7)$ & $31(10.4)$ & $<0.001$ \\
Satisfied & $173(54.3)$ & $244(81.9)$ & \\
\hline \multicolumn{4}{l}{ Values are presented as number $(\%)}$. \\
ECF: extended care facility.
\end{tabular}

Table 6. Reasons for Dissatisfaction in the Two Groups

\begin{tabular}{lc}
\multicolumn{1}{c}{ Answer } & $\begin{array}{c}\text { No. of } \\
\text { patients (\%) }\end{array}$ \\
\hline $\begin{array}{l}\text { Extended care facility group } \\
\text { Worse than expected rehabilitation (expertise, number }\end{array}$ & $11(22.0)$ \\
$\quad$ of rehabilitation sessions, etc.) & \\
Uncomfortable facilities (diet, bedding, etc.) & $9(18.0)$ \\
Insufficient postoperative care except rehabilitation & $30(60.0)$ \\
Home group & 23 \\
Unavailability of family & $5(21.7)$ \\
Psychological anxiety (complication, rehabilitation, & $11(47.8)$ \\
$\quad$ accident such as falling, etc.) & $7(30.4)$ \\
Lack of rehabilitation instruments
\end{tabular}

discharge to a non-home destination was reported to consume $36 \%$ of the total cost of care ${ }^{20)}$, measures must be taken to reduce the number of inpatient facility discharges to mitigate the total cost of patient care after TKA.

Some of the various demographic and perioperative variables reported from the West to favor an inpatient facility as discharge destination after TKA include older age $\mathrm{e}^{2,3,10,14,16,17,20,21,24)}$, female $\operatorname{sex}^{2,3,10,14,16,17,21)}$, higher comorbidity index ${ }^{1,2,14,16,17,19,21)}$, low socioeconomic status ${ }^{9,10)}$, non-white race ${ }^{2,10)}$, higher $\mathrm{BMI}^{16,17,21)}$, longer operation time ${ }^{16,17)}$, and longer length of stay in the acute-care hospital ${ }^{1,10-12,16,17,20,24)}$. In our study, we did not find any difference in age and sex distribution between the two groups. Similar to our findings, two retrospective studies on total knee and hip arthroplasties also did not find any differences in age and sex distributions among the discharge destination groups ${ }^{15,23)}$. Like most of the previous studies, our study revealed that among the patients with extended hospital stay, more were discharged to an ECF than to home. As in other studies, in our study, the patients in the ECF group tended to have higher BMIs than those in the home group, although the result was only close to reaching statistical significance $(\mathrm{p}=0.051)$. Besides the above-mentioned factors, we for the first time studied the difference in the number of bilateral TKAs between the home and ECF groups. More patients who 


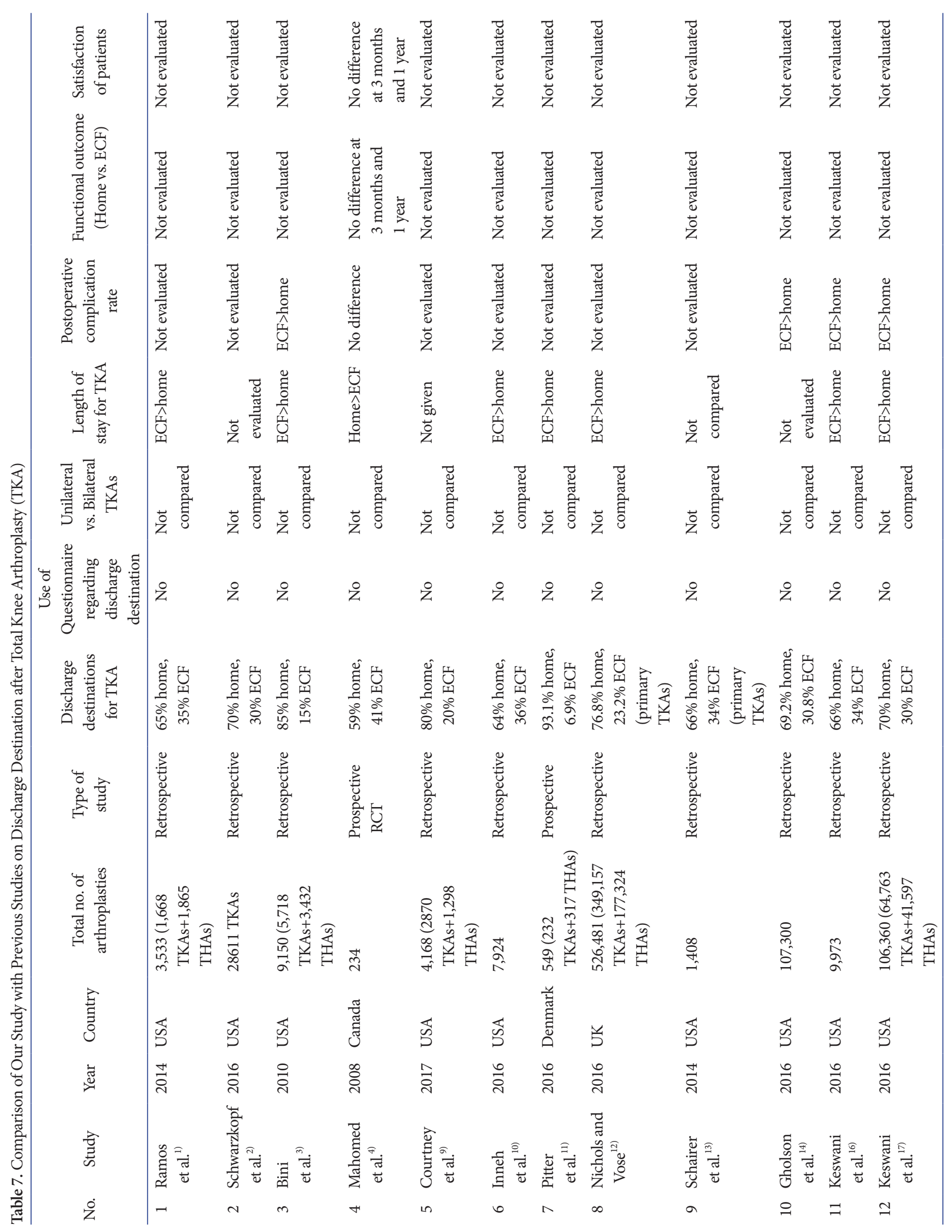




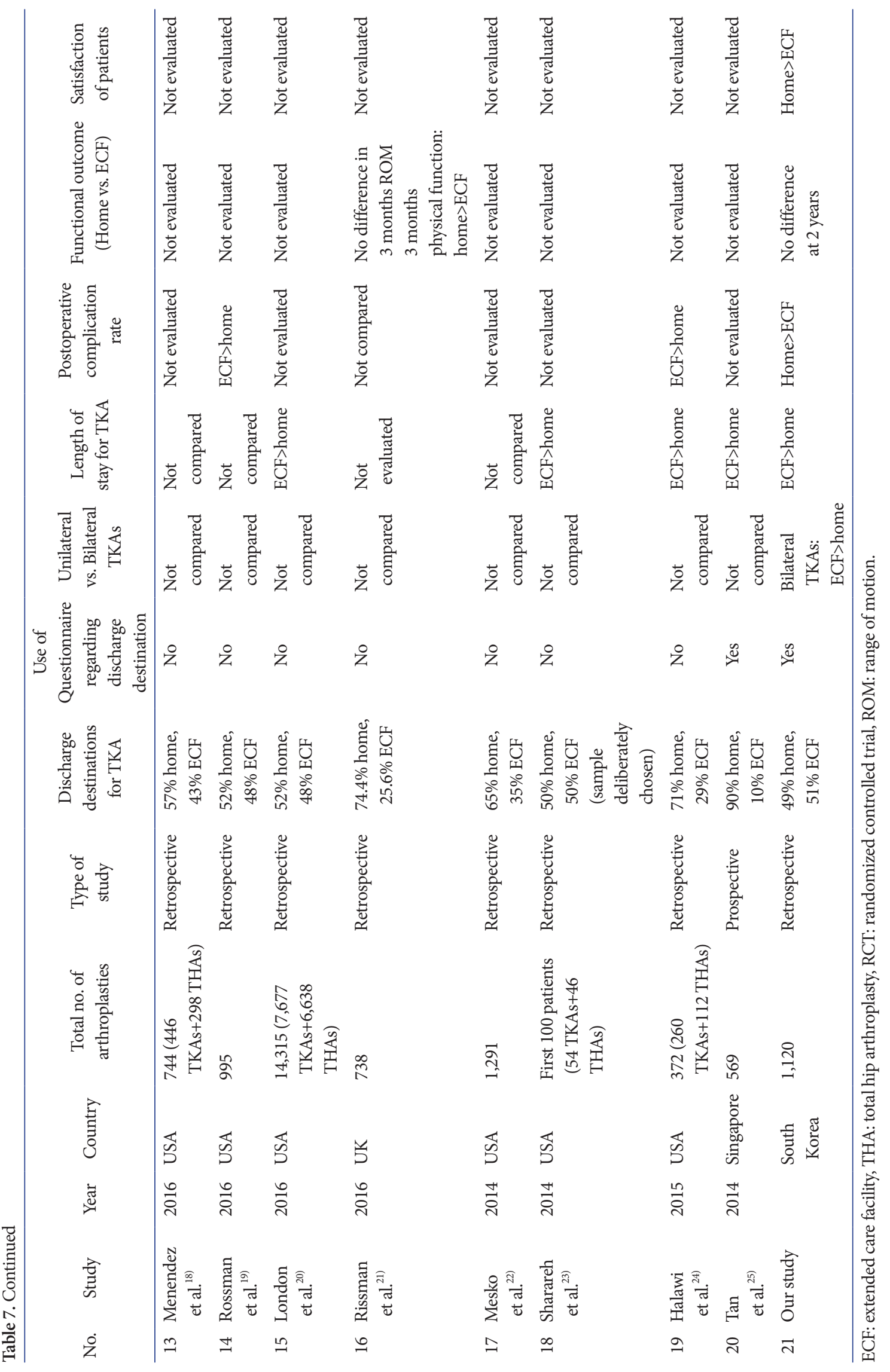


underwent bilateral TKA were discharged to an ECF than home. These results further signify the importance of patients' anticipations and apprehensions regarding their postoperative rehabilitative care in deciding their discharge location after TKA.

Home patients were found to have more complications within the first 3 months after TKA than ECF patients. Although the difference was remarkable, it did not reach statistical significance ( $\mathrm{p}=0.057$ ), probably because the complications were fewer overall and the sample size was too small to decipher any difference. Although a prospective randomized study found no difference in the postoperative complication rate in the two discharge destinations ${ }^{4}$, most of the other studies from the Western world reported increased rates of early complications in patients discharged to an ECF as compared with those discharged to home $e^{3,14,16,17,19,24)}$. The difference between our results and those of other studies could be because of the lower comorbidity profile of the patients discharged to ECFs in South Korea than that in Western countries. This hypothesis needs to be confirmed through future studies that evaluate the comorbidity index in the two discharge groups. Moreover, lack of a caregiver at home as admitted by a large number (45\%) of the patients discharged to home could also be a contributing factor.

Only a couple of studies have compared functional outcome between home and non-home discharge destinations ${ }^{4,21}$. However, none of these studies evaluated the outcome at 2 years' followup. We found no significant difference in functional outcome at 2 years between the two groups. In a retrospective study of 738 TKAs, the authors found that home-based rehabilitation was associated with greater 3-month postoperative patient-reported physical function improvement than non-home group, although no significant difference in ROM at 3 months was found ${ }^{21)}$. A prospective randomized study found no significant difference in functional outcome evaluated using WOMAC and SF-36 scores at 3-month and 1-year postoperative periods between the two groups $^{4}$. As functional outcome measures were reported to improve up to 2 years of follow-up after TKA ${ }^{26,27)}$, a difference in outcome at 2 years more comprehensively indicates the role of discharge destination. These results need to be communicated with patients, preoperatively, so that they can make informed decisions about their discharge destination.

Home-based rehabilitation was found to provide better patient satisfaction than ECF in our study. In the only other published study that compared patient satisfaction assessed using the Hip and Knee Satisfaction Scale between the home and non-home groups, the authors did not find any difference ${ }^{4}$. We believe that by asking the patients directly through our telephone survey, we were in a better position to elucidate satisfaction levels with the discharge destination. The patients in the ECF group reported that insufficient postoperative care besides rehabilitation was the chief reason for their dissatisfaction. This signifies the importance of improving the inpatient rehabilitation facilities in South Korea, which are not so well equipped with modern rehabilitation instruments. When the ECF options after TKA are compared, IRF is reported to have shorter length of stay than SNF with superior functional outcomes, although at an increased $\operatorname{cost}^{28,29)}$. On the other hand, SNF patients are reported to be more independent in self-care after discharge following lower-extremity joint replacements ${ }^{30}$. Since SNF facilities after TKA are not adequately developed in South Korea, attention needs to be given on improvement of the nursing facilities. Moreover, as psychological anxiety was the main cause of dissatisfaction in the home patients (48\%), adequate psychological counseling needs to be provided before discharging patients to home.

Our study had a number of strengths, including use of a standardized clinical pathway, use of validated outcome measures, and the 2 years of follow-up. A further strength was the relatively large proportion $(80 \%)$ of the original sample included in the analysis. Moreover, a post hoc power analysis confirmed the adequacy of the sample size. However, this study had some limitations that should be considered while interpreting the results. First, it was a single-institution-based study. Thus, whether the results are applicable to the TKA population of the country at large needs consideration. However, being a large-volume tertiary care referral institution, with patients coming from all parts of the country, we boast of a sufficiently heterogeneous patient population, similar to the national population. Second, as it was a retrospective study, selection bias cannot be ruled out. As we selected the consecutive patients from the two groups, an attempt was made to mitigate the bias. The other limitations included recall bias in the telephone survey and variable bias inherent in retrospective studies. We did not study the effect of race, insurance, socioeconomic status, comorbidity index, blood transfusions, and unplanned readmissions in our study. Additional comprehensive studies in the future are required to evaluate the influence of the above-mentioned variables on the discharge destination following TKA in South Korea.

\section{Conclusions}

ECF was slightly more popular than home as discharge destination after TKA, more so in bilateral cases and after prolonged hospital stay. However, home-based care had similar functional 
outcome at 2 years and higher patient satisfaction albeit with a higher tendency of complications. These results provide an insight into the status of discharge destinations after TKA in South Korea. Patients need to be adequately counseled and educated about the advantages and limitations of the two equally efficacious discharge destination options.

\section{Conflict of Interest}

No potential conflict of interest relevant to this article was reported.

\section{References}

1. Ramos NL, Karia RJ, Hutzler LH, Brandt AM, Slover JD, Bosco JA. The effect of discharge disposition on 30-day readmission rates after total joint arthroplasty. J Arthroplasty. 2014;29:674-7.

2. Schwarzkopf R, Ho J, Quinn JR, Snir N, Mukamel D. Factors influencing discharge destination after total knee arthroplasty: a database analysis. Geriatr Orthop Surg Rehabil. 2016;7: 95-9.

3. Bini SA, Fithian DC, Paxton LW, Khatod MX, Inacio MC, Namba RS. Does discharge disposition after primary total joint arthroplasty affect readmission rates? J Arthroplasty. 2010;25:114-7.

4. Mahomed NN, Davis AM, Hawker G, Badley E, Davey JR, Syed KA, Coyte PC, Gandhi R, Wright JG. Inpatient compared with home-based rehabilitation following primary unilateral total hip or knee replacement: a randomized controlled trial. J Bone Joint Surg Am. 2008;90:1673-80.

5. Insall JN, Dorr LD, Scott RD, Scott WN. Rationale of the Knee Society clinical rating system. Clin Orthop Relat Res. 1989;(248):13-4.

6. Bellamy N, Buchanan WW, Goldsmith CH, Campbell J, Stitt LW. Validation study of WOMAC: a health status instrument for measuring clinically important patient relevant outcomes to antirheumatic drug therapy in patients with osteoarthritis of the hip or knee. J Rheumatol. 1988;15:1833-40.

7. Ware JE Jr, Sherbourne CD. The MOS 36-item short-form health survey (SF-36): I. Conceptual framework and item selection. Med Care. 1992;30:473-83.

8. Angst F, Aeschlimann A, Stucki G. Smallest detectable and minimal clinically important differences of rehabilitation intervention with their implications for required sample sizes using WOMAC and SF-36 quality of life measurement instruments in patients with osteoarthritis of the lower extremities. Arthritis Rheum. 2001;45:384-91.

9. Courtney PM, Huddleston JI, Iorio R, Markel DC. Socioeconomic risk adjustment models for reimbursement are necessary in primary total joint arthroplasty. J Arthroplasty. 2017; 32:1-5.

10. Inneh IA, Clair AJ, Slover JD, Iorio R. Disparities in discharge destination after lower extremity joint arthroplasty: analysis of 7924 patients in an urban setting. J Arthroplasty. 2016;31:2700-4.

11. Pitter FT, Jørgensen CC, Lindberg-Larsen M, Kehlet H; Lundbeck Foundation Center for Fast-track Hip and Knee Replacement Collaborative Group. Postoperative morbidity and discharge destinations after fast-track hip and knee arthroplasty in patients older than 85 years. Anesth Analg. 2016;122:1807-15.

12. Nichols CI, Vose JG. Clinical outcomes and costs within 90 days of primary or revision total joint arthroplasty. J Arthroplasty. 2016;31:1400-6.

13. Schairer WW, Vail TP, Bozic KJ. What are the rates and causes of hospital readmission after total knee arthroplasty? Clin Orthop Relat Res. 2014;472:181-7.

14. Gholson JJ, Pugely AJ, Bedard NA, Duchman KR, Anthony CA, Callaghan JJ. Can we predict discharge status after total joint arthroplasty? A calculator to predict home discharge. J Arthroplasty. 2016;31:2705-9.

15. Phan DL, Ahn K, Rinehart JB, Calderon MD, Wu WD, Schwarzkopf R. Joint arthroplasty perioperative surgical home: impact of patient characteristics on postoperative outcomes. World J Orthop. 2016;7:376-82.

16. Keswani A, Weiser MC, Shin J, Lovy AJ, Moucha CS. Discharge destination after revision total joint arthroplasty: an analysis of postdischarge outcomes and placement risk factors. J Arthroplasty. 2016;31:1866-72.

17. Keswani A, Tasi MC, Fields A, Lovy AJ, Moucha CS, Bozic KJ. Discharge destination after total joint arthroplasty: an analysis of postdischarge outcomes, placement risk factors, and recent trends. J Arthroplasty. 2016;31:1155-62.

18. Menendez ME, Schumacher CS, Ring D, Freiberg AA, Rubash HE, Kwon YM. Does "6-clicks" day 1 postoperative mobility score predict discharge disposition after total hip and knee arthroplasties? J Arthroplasty. 2016;31:1916-20.

19. Rossman SR, Reb CW, Danowski RM, Maltenfort MG, Mariani JK, Lonner JH. Selective early hospital discharge does not increase readmission but unnecessary return to the emergency department is excessive across groups after pri- 
mary total knee arthroplasty. J Arthroplasty. 2016;31:1175-8.

20. London DA, Vilensky S, O’Rourke C, Schill M, Woicehovich L, Froimson MI. Discharge disposition after joint replacement and the potential for cost savings: effect of hospital policies and surgeons. J Arthroplasty. 2016;31:743-8.

21. Rissman CM, Keeney BJ, Ercolano EM, Koenig KM. Predictors of facility discharge, range of motion, and patientreported physical function improvement after primary total knee arthroplasty: a prospective cohort analysis. J Arthroplasty. 2016;31:36-41.

22. Mesko NW, Bachmann KR, Kovacevic D, LoGrasso ME, O'Rourke C, Froimson MI. Thirty-day readmission following total hip and knee arthroplasty: a preliminary single institution predictive model. J Arthroplasty. 2014;29:1532-8.

23. Sharareh B, Le NB, Hoang MT, Schwarzkopf R. Factors determining discharge destination for patients undergoing total joint arthroplasty. J Arthroplasty. 2014;29:1355-8.

24. Halawi MJ, Vovos TJ, Green CL, Wellman SS, Attarian DE, Bolognesi MP. Patient expectation is the most important predictor of discharge destination after primary total joint arthroplasty. J Arthroplasty. 2015;30:539-42.

25. Tan C, Loo G, Pua YH, Chong HC, Yeo W, Ong PH, Lo NN, Allison G. Predicting discharge outcomes after total knee replacement using the risk assessment and predictor tool. Physiotherapy. 2014;100:176-81.

26. Nerhus TK, Heir S, Thornes E, Madsen JE, Ekeland A. Time-dependent improvement in functional outcome following LCS rotating platform knee replacement. Acta Orthop. 2010;81:727-32.

27. Nilsdotter AK, Toksvig-Larsen S, Roos EM. A 5 year prospective study of patient-relevant outcomes after total knee replacement. Osteoarthritis Cartilage. 2009;17:601-6.

28. Herbold JA, Bonistall K, Walsh MB. Rehabilitation following total knee replacement, total hip replacement, and hip fracture: a case-controlled comparison. J Geriatr Phys Ther. 2011;34:155-60.

29. Walsh MB, Herbold J. Outcome after rehabilitation for total joint replacement at IRF and SNF: a case-controlled comparison. Am J Phys Med Rehabil. 2006;85:1-5.

30. Mallinson TR, Bateman J, Tseng HY, Manheim L, Almagor O, Deutsch A, Heinemann AW. A comparison of discharge functional status after rehabilitation in skilled nursing, home health, and medical rehabilitation settings for patients after lower-extremity joint replacement surgery. Arch Phys Med Rehabil. 2011;92:712-20. 